\title{
Correction to: Electrochemical Impedance Spectroscopy Characterization of Silicon-Based Electrodes for Li-Ion Batteries
}

\author{
Maciej Ratynski ${ }^{1}$ - Bartosz Hamankiewicz ${ }^{1} \cdot$ Michał Krajewski $^{1} \cdot$ Maciej Boczar $^{1}$ • Dominika A. Buchberger ${ }^{1}$.
} Andrzej Czerwinski ${ }^{1}$

Published online: 14 March 2020

(C) Springer Science+Business Media, LLC, part of Springer Nature 2020

Correction to: Electrocatalysis https://doi.org/10.1007/s12678-019-00573-y

There was a typo in author name. The correct author name should be: Bartosz Hamankiewicz.

The authors regret the error.

The online version of the original article can be found at https://doi.org/ 10.1007/s12678-019-00573-y

$\triangle$ Bartosz Hamankiewicz

bhamankiewicz@chem.uw.edu.pl

1 University of Warsaw, Pasteura 1, 02-093 Warsaw, Poland 